\title{
Application of Goal-oriented Approach in College English Vocabulary Teaching
}

\author{
Ting Xiao ${ }^{a}$, Qian Yang ${ }^{b}$ \\ School of English, Chongqing Nanfang Translators College of SISU, Chongqing 401120, China \\ alilo822@126.com, b9622741@qq.com
}

Keywords: Goal-oriented, college English, vocabulary teaching.

\begin{abstract}
Goal-oriented college English teaching mode consists of three parts: formulation, actualization and evaluation of the teaching goal. Vocabulary teaching is the main content in college English education, so it is significant for English education. Under the direction of goal-oriented approach, college English vocabulary teaching includes: teaching goal setting, teaching content planning, teaching methods selecting and teaching evaluating, etc. The teaching methods emphasize on using various teaching methods to obtain the best way to learn English vocabulary under integrated planning and teaching practice.
\end{abstract}

\section{Introduction}

Goal-oriented education theory is based on psychology and pedagogy research of twenty century of domestic psychologists. [1] It's a theory mainly study scientific education and classroom teaching. It reflected the newest achievements of contemporary psychology research. It also reflected the new development of human's cognitive process research and its application in teaching planning. The core of this theory is that different knowledge should be taught in different teaching methods.

Teaching goals are the direction of teaching activities' application and expecting results. It's the start and destination of all the teaching activities. Teaching goals are the specific teaching requirements of teachers', which are on the basis of syllabus, the teaching materials and the characters of subject curriculum; they are the final abilities and comprehensive knowledge of students' after series of teaching activities; and they are the final expectation of phase teaching demand. [2] Under the new curriculum, teaching goals include three parts knowledge and skills, process and methods and emotion attitude and value system. Teaching goals go through all the procedures of teaching activities, and they restrict every step of teaching activities. A scientific and appropriate teaching goal will guide the teachers' teaching and the students' study, which is the foundation of enhancing teaching qualities. [3]

Goal-oriented education is a teaching method which combined teaching ideas, teaching goals, teaching activities and teaching evaluation. It takes modern teaching theory as a guide, three-dimensional target as the center, feedback and regulation as strategies and enhancing qualities as a goal; it's also creative teaching mode on the basis of traditional combination of intellectual and non-intellectual factors. [4]

In English vocabulary teaching, the application of goal-oriented education could make more obvious goals and demands for teaching and learning activities. It emphasizes on overall development of students, and completely abandons cramming-method of teaching in the past. Under the control of teaching goal, teachers give initiative back to the students making them the masters of study, who can explore, discover, and learn academic knowledge. According to the discussion, goal-oriented education is a teaching method, which is under the guide of teachers, taking teaching goal as guide and making students study by themselves actively. 


\section{Existing Problems}

Goal-oriented teaching theory implied two new concepts: learning and teaching. The most obvious character is evolution of learning theory. In traditional teaching theory, students are passive receivers. So during the process of teaching, cramming education gradually suppresses the enthusiasm and initiative of learning, which lead to "high scores and low abilities" in school and no abilities to learn in society. However, modern learning psychology define knowledge as, information organization, which is obtained by mutual effects of individuals and their environment. For students the most important task of classroom education is to get knowledge and skills and to apply them in practical questions. So teaching goal setting, teaching content and teaching methods selecting are related to original knowledge and skills and development potential. According to the theory, to strengthen the dominant role of students, teachers should understand students' qualities first in order to tell their original level and potential level.

According to the survey, English vocabulary teaching in college has lots of problems:

Teachers have some extreme ideas about vocabulary teaching. For example, some of teachers consider there's no need to have direct vocabulary classes in college. Vocabulary teaching methods of some teachers are not reasonable. For example, most of teachers only concentrate on the meaning of certain vocabulary while neglect cultural connotation and pragmatic meaning.

Teachers ignore guidance on students' learning strategies of vocabulary. For example, some teachers don't pay attention to after class remembering skills.

There are some difficult problems in vocabulary teaching. For example, it is difficult for students to understand connection of meanings of polysemy.

The cause of these problems is complicated.

In concepts:

Some teachers think direct vocabulary teaching is non-communicative, and college students have self-study abilities on vocabulary. So there's no need to have vocabulary classes.

Some teachers think students have poor fundamental skills in English, so they should teaching in Chinese or all most Chinese.

In teaching methods:

Teachers ignore cultivating on communicative skills of students, and only concentrate on teacher-oriented classes.

Teachers ignore arousing students' attention, and the form of the classroom is dull.

Teachers explain meanings of vocabulary isolated, and don't pay attention to the connection between vocabulary and context.

Teachers pay no attention to theoretical accomplishment and neglect the teaching of vocabulary cultural connotation and pragmatic meaning.

In teaching difficulties:

Meanings of polysemy are very hard for students to understand and remember;

Students have low storage on language chunks, so the expression of students are poor.

\section{Strategies of Solving the Problems}

\subsection{Attach Importance to the Guiding Role of Teaching Goal.}

The function of teaching goal contains: guiding on learning, guiding on teaching, guiding on measuring and guiding on evaluation. So in goal-oriented education, setting goal is of vital importance, and it is the first step of scientific education. The teaching of teachers and the learning of students have to aim at the goal. In vocabulary teaching process, teachers should cultivate on students' passive vocabulary awareness. Vocabulary awareness means learners' psychological disposition on awareness, emotion and attitude. When students encounter with lots of new words, they always felt that learning is very difficult, so I can't learn and I feel frustrated. For the condition, teachers should let the students understand: 
Encounter with new vocabulary is a normal thing, and it's a good thing. Because it tells us there are something new deserve our attention, which may help us making progress. The huge numbers and complicated meanings of English vocabulary is the inevitable result of social development, and it's the advantage of English.

English vocabulary reflect the boundless universe, it's the one of the most important content, which should be developed by the learners.

The subject of vocabulary acquisition is students, and no one can replace. Massive vocabulary can be only accumulated by hardworking of oneself.

There's no the best, the fastest and the unique ways of vocabulary learning. Students can only look for suitable ways for themselves to learn vocabulary.

\subsection{Add Teaching Task Analysis in Teaching Planning.}

For scientific teaching, teachers should add teaching task analysis in classroom teaching planning. The first step of teaching task analysis is to make sure types of study results including in teaching goal; the next step is to make sure students' starting capabilities; the last one is to analyze the achievement of goal, which is from the start to the end of teaching goal. According to "Involvement Load Hypothesis" of Lauer and Holstein(2001), teachers should pay more attention to give more learning tasks related to vocabulary learning to students.[5] If the learning tasks require more on learners involvement, in other words they stimulate more efforts on vocabulary knowledge of "requirement" and "searching", then the effect of vocabulary acquisition will be better. It may compensate for the insufficient of incidental vocabulary learning of reading. We should:

Set up right and profound understanding on vocabulary learning.

Arouse urge on vocabulary learning.

Try to search for all the meanings of the vocabulary.

Analyze and compare different words, one word with lots of meanings and different collocations.

\subsection{Decide Teaching Strategies According to Task Analysis.}

Distinguish learning types according to task analysis to achieve integrate of learning goal and teaching strategies. It is why goal-oriented teaching method can optimize connotative meaning of teaching and is the core of its practical meaning. Teaching strategies includes selecting of teaching procedures, teaching methods and teaching media and so on. The presenting mode of vocabulary is a procedure which shows the target vocabulary to the learners in a certain way and method. It includes knowledge information of a word in different levels, for example, the form, the sound, the meaning, the syntax, the connotation, the application and the exemplification, etc. Through various ways of presenting, teachers strengthen the vocabulary understanding of the learners with helping the learners get rich and complete vocabulary information through presenting procedure, making target vocabulary become complete storage in mental lexicon and go into long-term memory, which will be activated and extracted in following study.

\section{Problems That Need to Pay Attention to in Teaching Procedure}

Firstly, in process of goal-oriented education, the aim and the task setting are very important. Learning process consists of setting goals, solving problems and completing task. The setting of good goal would conquer blindness and arbitrariness of personalized study and could make learners master the teaching task of the teachers in the procedure of realizing the goal. During and after goal-oriented education process, teachers should add guidance and conclusion for students. Teachers also should pay attention to making efforts on creating conditions for students to complete their tasks, however teachers should avoid interference and try their best to keep the curiosity of students, and encourage students to find and ask questions actively, and to study positively.

Secondly, teachers should pay attention to planning abundant and interesting teaching strategies, which asks the teachers to prepare abundant multimedia materials and files, make scientific and interesting courseware before classes. In the meantime, teachers should have classroom management experiences, which ensures the atmosphere and teaching speed of classes. 
Thirdly, in the process of goal-oriented education, the key is the interests of students. It asked the students to keep motivation during classes. If students loose high motivation in teaching process, then goal-oriented education would become meaningless. So during the teaching process, teachers should use multimedia properly to arouse students' initiative in study.

\section{Conclusion}

Application of goal-oriented education in college English vocabulary teaching wants to connect goal of college English study, study contents, study needs of students, teaching ways and academic evaluation. It focuses on discussing how to get the best effect of learning under integrated planning through various ways of teaching.

Goal-oriented education teaching method is on the basis of humanism and constructive learning theory. It integrated the characters of exploring study, cooperating study and personalizing study. It is helpful to arouse learning interest of students, to achieve teaching goal, to develop initiative of learning and to improve the effect of vocabulary learning. However, the teaching methods still need to be explored and completed in teaching practice.

\section{References}

[1]. Anthony S, Badoni's, David F, Salibury. Et al. Development and Validation of Models in Instruction Design. London: Educational Technology, 1994, p26-32.

[2]. Anglo T. A., Cross P. K. et al. Classroom Assessment Techniques, San Francisco: Josser -Brass, 1993, p. 75.

[3]. Deng Nanchang, et al. Language and Culture. Beijing: Foreign Language Teaching and Research Press, 1989, p. 56-58.

[4]. Hu Zhongfeng, et al. Educational Measurement and Evaluation, Guangzhou: Guangdong Higher Education Press, 2006(2), p.17.

[5]. Information on: http://wenku.baidu.com/view/a4daab8783d049649b6658c8.html 2012.6.12 